\title{
Pendampingan Dan Peningkatan Literasi Siswa Melalui Gerakan Membaca Di Masa Pandemi Di Desa Mentuda Kecamatan Lingga Kabupaten Lingga
}

\author{
Talizaro Tafonao $^{1}$, Fransiskus Irwan Widjaja ${ }^{2}$, Sabar Manahan Hutagalung ${ }^{3}$, Haposan \\ Simanjuntak $^{4}$, Vicky B. G. D. PAAT ${ }^{5}$, Sihar Lamhot Simatupang ${ }^{6}$, Juntriman Purba ${ }^{7}$ \\ 1,4 Prodi PAK, STT REAL Batam \\ 2, 3, 5, 6, 7 Prodi Teologi, STT REAL Batam \\ talizarotafonao@gmail.com
}

\begin{abstract}
The purpose of this service is to maximize children's ability to read and write in Mentuda Village, Lingga Regency, while studying at home. The impact of Covid-19 has disrupted the learning system in various schools including children in Mentuda Village. This activity is carried out based on the problems experienced by the children as explained in this article. The method of implementing this community service is lectures, discussions, simulations and practices on how to read correctly. After this activity was carried out, the results obtained were that about $90 \%$ of children read well as the results in the explanation in this article. This can be seen in every activity carried out by the children who are very enthusiastic in participating in each session that has been arranged by the team. This means that activities like this are very effective to continue to be carried out for children.
\end{abstract}

Keywords: Mentoring, Improving Student Literacy, Reading Movement, Mentuda Village, Lingga

\begin{abstract}
Abstrak
Tujuan pengabdian ini adalah untuk memaksimalkan kemampuan anak dalam baca dan tulis di Desa Mentuda Kecamatan Lingga Kabupaten selama belajar di rumah. Dampak dari Covid-19 ini telah mengganggu sistem belajar di berbagai sekolah termasuk anak-anak yang ada di Desa Mentuda. Kegiatan ini dilakukan berdasarkan masalah yang dialami oleh anak-anak sebagaimana penjelasan dalam artikel ini. Metode pelaksanaan pengabdian masyarakat ini yakni ceramah, diskusi, simulasi dan praktik tentang cara membaca yang benar. Setelah kegiatan ini dilakukan, hasil yang dapatkan adalah anak-anak membaca dengan baik sekitar $90 \%$ sebagaimana hasil dalam penjelasan dalam artikel ini. Hal ini nampak pada setiap kegaitan yang dilakukan anak-anak sangat antusias dalam mengikuti setiap sesi yang telah diatur oleh tim. Artinya bahwa kegiatankegiatan seperti ini sangat efektif untuk terus dilakukan kepada anak-anak.

Kata kunci: Pendampingan, Peningkatan Literasi Siswa, Gerakan Membaca, Desa Mentuda, Lingga
\end{abstract}

\section{PENDAHULUAN}

Sejak adanya Covid-19 ini memiliki dampak cukup besar dalam kehidupan masyarakat, seperti kesehatan, ekonomi, pekerjaan dan sosial dan lain sebagainya. Tidak hanya itu yang mengalami dampak dari pandemi, tetapi dunia pendidikan juga tidak luput mengalami akibatnya dari Covid-19. Sehingga tidak heran jika selam pelaksanaan pembelajaran di masa pandemi tidak berjalan dengan baik sesuai dengan tuntutan pemerintah. Dan dampak dari pandemi ini tidak hanya dialami oleh anakanak yang ada di kota namun hal ini juga dialami oleh anak-anak yang ada di pelosok. Anak-anak yang sudah terbiasa belajar di sekolah sudah pasti akan merasakan hal yang berbeda tentang belajar di rumah atau belajar daring.

Ada beberapa keluhan yang dialami oleh anak-anak selama belajar di masa pandemi yakni Jaringan Internet yang Lambat, Harga Kuota Internet yang Mahal, Terbatasnya Akses ke Perangkat Komputer dan Smartphone, Banyaknya Gangguan di Rumah, Guru dan Pelajar Masih Belum Lihai Menggunakan Teknologi Digital, Sulit untuk Interaktif, dan Siswa memilih Bermain daripada belajar. 
Sekalipn demikan, bagi anak-anak yang ada yang ada di kota yang memiliki fasilitas cukup maka problem-prolem di atas tidak terlalu kelihatan karena mereka telah terbiasa dengan menggunakan teknologi. Tetapi berbeda dengan anak-anak yang ada di desa, anak-anak yang di desa sangat susah mengikuti pembelajaran dengan menggunakan daring, apa lagi fasilitasnya yang sangat minim, mulai dari listrik, jaringan internet, leptop dan gawai. Dalam kegiatan yang dilakukan oleh Purnama, dkk di di Desa Cabean menemukan rata-rata anak di Desa tersebut tidak memiliki smartphone selama belajar di masa pandemi ini dan ditambah lagi orang tua tidak memahami materi pelajaran putra-putrinya. ${ }^{1}$

Masalah-masalah seperti ini juga dialami oleh anak-anak yang ada di Desa Mentuda Kecamatan Lingga Kabupaten Lingga, dimana anak-anak di sana sejak diberlakukan pembelajaran online oleh pemerintah anak-anak di Desa tersebut hampir tidak pergi di sekolah bahkan mereka pergi membantu orang tua bekerja di ladang. Dan sebagian besar bermain-main di luar rumah. Informasi seperti ini didapatkan pada saat tim melakukan observasi dan pengamatan tentng kehidupan masyarakat pada 31 Januari - 12 Februari 202.

Berdasarkan hasil observasi dan pengamatan langsung yang dilakukan oleh tim di lapangan maka tim pengabdian masyarakat dari Sekolah Tinggi Teologi Real Batam mengadakan pendampingan dalam rangka meningkatkan literasi baca kepada anak-anak agar anak-anak tetap merasakan suasana belajar sekalipun tidak berada di sekolah. Selain itu menurut Yuhenita dkk, kegiatan pendampingan seperti ini sangat penting dilakukan di masa pandemi demi menumbuhkan motivasi untuk tetap belajar. ${ }^{2}$ Karena belajar di rumah merupakan hal baru bagi anak-anak dan orang tua. Dengan melaksanakan kegiatan pendampingan seperti ini anak yang di Desa Mentuda anak-anak dan orang tua memiliki pemahaman yang benar bahwa belajar itu tidak hanya dilakukan di sekolah. Pengajaran tentang kesadaran seperti ini yang menjadi poin penting dalam kegiatan pengabdian ini selama beberapa hari. Karena dalam diskusi dengan orang tua anak menemukan bahwa rata-rata anakanak mereka masih belum pintar beca tulis. Menurut penjelasan warga tersebut bahwa anak-anak disini sangat minim minat dalam belajar di sekolah. Hal ini terlihat sebelum adanya Covid-19, anakanak lebih memilih bermain sama teman-teman sebayanya daripada pergi ke sekoah, bahkan ada anak hanya satu kali seminggu pergi sekolah. Apa lagi ketika adanya Covid-19 peserta didik lebih senang ketika sekolah di liburkan. Sehingga tidak heran jika masih ada anak-anak tersebut banyak yang belum bisa baca dan tulis.

Apa yang disampaikan oleh warga di atas hal itu benar adanya, pada saat tim mulai mengajar anak-anak tersebut masih banyak belum bisa baca dan tulis. Itulah sebabnya pentingnya sekali dilakukan kegiatan ini untuk menumbuhkan kesadaran anak-anak serta orang tua bahwa belajar itu sangat penting. Dalam kegiatan selama kurang lebih empat hari, para tim memanfaatkan waktu untuk mengajar dan memberi nasihat kepada orang tua orang tua tidak hanya fokus mencari nafkah, tetapi orang tua harus memberi perhatian kepada anak untuk dimotivasi belajar. Tujuan pengabdian ini adalah untuk memaksimalkan kemampuan anak dalam baca dan tulis.

\section{Metode Penelitian}

Metode yang dilakukan dalam kegiatan ini adalah, yaitu ceramah, diskusi, simulasi dan praktik tentang belajar yang benar. Kegitan pengabdian ini ada beberapa tahapan yang dialakukan, yaitu (1) tahapan persiapan. Tahapan pertama ini para tim terlebih dahulu meminta ijin kepada masyarakat setempat dalam melaksanakan kegiatan ini supaya anak-anaknya dapat diijinkan untuk belajar selama

\footnotetext{
${ }^{1}$ Adi Indra Purnama et al., "DAMPAK PANDEMI COVID-19 TERHADAP PEMBELAJARAN DARING SEKOLAH DASAR DI DESA CABEAN KECAMATAN DEMAK," Jurnal Online Internasional \& Nasional Vol. 7 No.1, Januari - Juni 2019 Universitas 17 Agustus 1945 Jakarta 53, no. 9 (2019): 1689-1699.

${ }^{2}$ N N Yuhenita, Y M Majid, and A Murat, "Pendampingan Dalam Menghadapi Pembelajaran Di Masa Pandemi Bagi Warga Dusun Macanan,” Selaparang : Jurnal Pengabdian Masyarakat Berkemajuan 4, no. April (2021): 215-219.
} 
kegitan berlangsung. (2) tahapan pelaksanaan. Pelaksanaan kegiatan ini dilakukan pada 6 sampai 9 April 2021 di Desa Mentuda Kecamatan Lingga Kabupaten Lingga selama empat hari. (3) tahap evaluasi. Kegiatan evaluasi dilakukan untuk mengetahui sejauh mana kegiatan ini bermanfaat kepada mitra/anak sekolah. Setelah itu, diamati apa saja kendala yang dihadapi oleh anak-anak pada saat belajar.

\section{HASIL DAN PEMBAHASAN Belajar menulis}

Anak-anak yang ada di di Desa Mentuda ini masih banyak yang belum bisa menulis. Secara usia mereka telah memasuki usia anak sekolahan. Dalam kegiatan ini para tim mengajarkan anak-anak untuk terlatih menulis dengan disediakan buku tulis dan pulpen. Aktifitas seperti ini anak-anak jadi senang karena mereka merasa diperhatikan. Selain diperhatikan merasa senang karena dapat hal-hal baru tim pengajar.

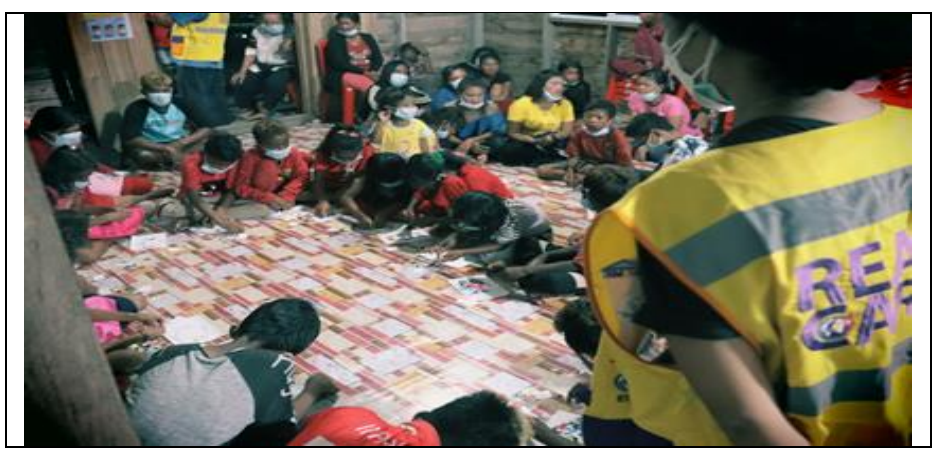

Gambar 1. Tim PkM Mengajar Anak-anak belajar menulis

\section{Belajar membaca}

Selain mereka diajar menulis anak-anak ini dilatih untuk membaca. Dalam pendahuluan tadi sudah disinggung bahwa anak-anak yang di Desa tersebut masih ada belum bisa membaca. Dengan metode seperti ini anak-anak terbantu menambah pengetahuan membaca serta ada keberanian untuk maju membaca.

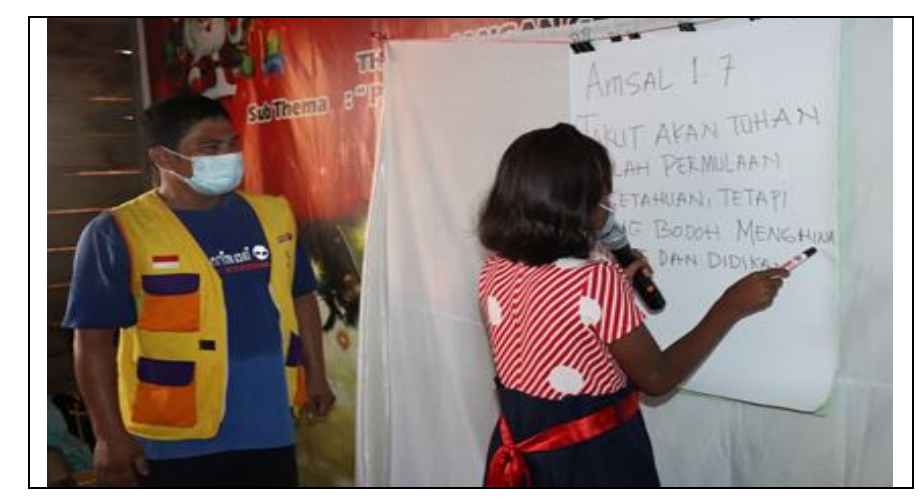

\section{Gambar 2. Tim PkM Mengajar anak-anak belajar Membaca}

\section{Belajar diskusi}

Selain menulis dan membaca anak-anak ini diajak untuk berdiskusi dengan dibagi dalam beberapa kelompok. Tujuan diskusi ini adalah melatih anak-anak untuk menyampaikan pendapatnya serta untuk dilatih bertanya. Setiap kelompok berbeda topik yang dibahas. Dengan cara seperti ini anak mulai berani menyampaikan pendapatnya. 


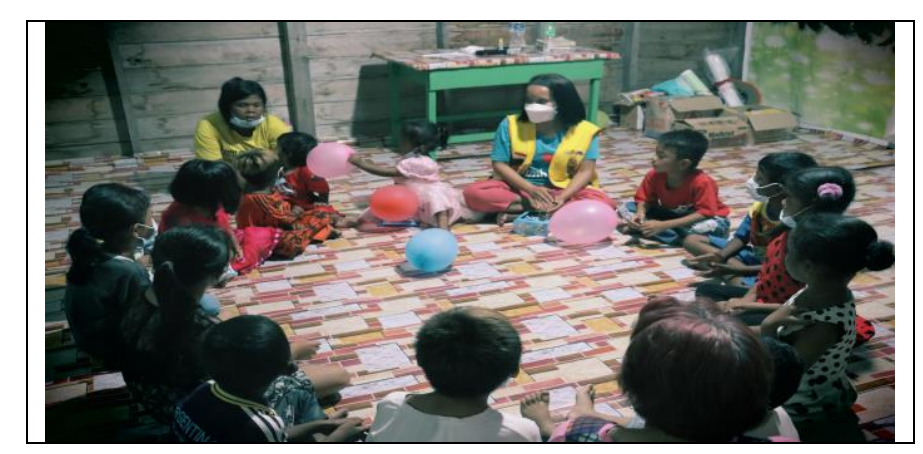

\section{Gambar 3. Tim PkM Mengajar anak-anak belajar dalam Group Diskusi}

Membaca salah satu aktifitas yang tidak bisa diabaikan oleh setiap anak. Dengan membaca dapat meningkat pengetahuan setiap anak. Anak yang suka membaca dan menulis sudah pasti akan lebih banyak mengetahui hal-hal baru dibandingkan dengan anak-anak lain yang tidak pernah belajar sama sekali. Hal ini juga yang diutarakan oleh Irdawati membaca adalah salah satu kegiatan untuk meningkatkan kemampuan berbahasa yang bersifat reseptif. Reseptif maksudnya orang yang suka membaca pasti banyak mendapatkan informasi, ilmu pengetahuan, dan pengalaman-pengalaman baru. ${ }^{3}$

Aktifitas dalam membaca bukan hal yang mudah dilakukan oleh setiap anak karena dalam membaca tidak hanya sekedar melafalkan, tetapi banyak hal yang dilibatkan yakni aktivitas visual, berpikir, psikolinguistik, dan metakognitif. Secara linguistik, membaca merupakan proses pembacaan sandi (decoding process). Artinya dalam kegiatan membaca ada upaya untuk menghubungkan katakata tulis (written word) dengan makna bahasa lisan (oral language meaning). Dengan kata lain bahwa kegiatan membaca merupakan kegiatan mengubah tulisan/cetakan menjadi bunyi-bunyi yang bermakna. Oleh karena itu dalam mengatasi setiap problem dalam membaca terhadap anak maka diperlukan suatu gerakan. Gerakan yang dimaksud oleh penulis disini adalah gerakan literasi. Gerakan literasi ini salah satu cara mendorong anak-anak untuk membaca. Gerakan literasi tidak hanya menjadi tanggung jawab pemerintah, tetapi juga tanggung jawab semua pemangku kepentingan termasuk dunia usaha, perguruan tinggi, organisasi sosial, pegiat literasi, orang tua, dan masyarakat. Oleh karena itu, keterlibatan publik dalam setiap kegiatan literasi menjadi sangat penting untuk memastikan dampak positif dari gerakan peningkatan daya saing bangsa. ${ }^{4}$

Menurut hemat Irna bahwa bangsa yang maju tidak hanya mengandalkan kekayaan alamnya saja, tetapi bangsa yang maju dan besar adalah bangsa yang suka berliterasi atau membaca. ${ }^{5}$ Indonesia ini masih perlu didorong dalam berliterasi, kalah jauh dengan negera-negara lain yang sangat jauh maju terlebih dahulu. Gerakan membaca harus dimulai sejak dini, yakni di mulai dari anak-anak usia taman kanak-kanak. Usia seperti ini salah satu kunci dalam mengenalkan setiap huruf agar kelak menjadi anak yang suka membaca. Dan inilah yang dilakukan oleh tim di Desa Mentuda. Anak-anak yang disana senang ketika diajar dengan baca tulis.

Selama pandemi sudah jarang bertemu dengan guru karena sekolah mereka di liburkan dan inisiatif guru dan orang tua sangat rendah dalam mengajarkan anak-anak dalam belajar. Menurut Nugroho bahwa kebiasaan membaca bagi anak tidak akan muncul dengan sendirinya tanpa diawali orang tua membaca, memperkenalkan buku bacaan, menyediakan bahan bacaan dan lingkungan yang

\footnotetext{
${ }^{3}$ Irdawati; Yunidar; dan Darmawan, "Meningkatkan Kemampuan Membaca Permulaan Dengan Menggunakan Media Gambar Kelas 1 Di Min Buol, ISSN 2354-614X," Jurnal Kreatif Tadulako Online 5, no. 4 (2017): 1-14.

${ }^{4}$ Agriani Stevany Kadiwanu, "Gerakan Literasi Nasional, Gerakan Bersama Demi Mencerdaskan Kehidupan Bangsa," BP PAUD DIKMAS NTT.

${ }^{5}$ Irna, "Menumbuhkan Minat Baca Anak Usia Dini Melalui Implementasi Literasi Keluarga," Fascho Kajian Pendidikan dan Sosial Kemasyarakatan 1, no. 1 (2019): 15-34.
} 
suka membaca. ${ }^{6}$ Artinya orang tua harus memiliki inisiatif dalam mendidik anak-anak dalam membaca. Orang tua harus memiliki pemahaman bahwa sekolah itu sangat penting bagi anak-anak.

Menurut Rohman bahwa setiap anak yang dilahirkan memiliki bibit menjadi jenius, namun setelah mereka masuk sekolah hanya sebagian kecil dari mereka yang mendapatkan predikat jenius. Apa yang menyebabkan hal ini bisa terjadi? Menurutnya karena budaya membaca sangat lemah sehingga hal itu berdampak pada kemajuan pengetahuan anak. Oleh karena itu peran keluarga sangat diperlukan untuk mendukung anak untuk semanagt membaca. ${ }^{7}$

Berdasarkan penjelasan dan upaya-upaya yang telah dipaparakan di atas maka dalam kegaiatan pembinaan ini ada beberapa hal yang dilakukan dalam meningkatkan literasi pada anak, adalah (1) kegiatan pembiasaan dalam membaca. Kegiatan seperti ini anak-anak dapat dilatih untuk membaca dalam hati, membaca nyaring, dan menyimak dengan tujuan adalah untuk meningkatkan rasa cinta membaca di luar pelajaran, meningkakan rasa percaya diri, dan menumbuhkembangkan penggunaan berbagai sumber bacaan serta dapat memanfaat waktu yang ada. (2) kegiatan pengembangan. Kegiatan dalam pengembangan ini adalah lanjutan dari kegiatan pembiasaan. Artinya anak-anak didorong untuk menunjukkan keterlibatan pikiran dan emosinya dalam proses membaca. Langkah ini dapat dilakukan melalui kegiatan produktif secara lisan maupun tulisan. (3). Kegiatan melibatkan anak-anak dalam membaca. Melibatkan anak dalam membaca salah kunci utama untuk menanamkan kebiasan baik dalam membaca. Anak yang sering dilibatkan dalam membaca akan lebih mudah diarahkan.

\section{SIMPULAN}

Kegiatan pengabdian yang dilakukan di Desa Mentuda Kecamatan Lingga Kabupaten Lingga telah berjalan dengan baik sesuai dengan tujuan dari pengabdian masyarakat. Hasil kegiatan dari pengabdian masyarakat ini dapat memberikan dampak positif kepada anak-anak, yaitu (1) ada kesadaran dalam membaca. (2) ada komunitas bersama. (3) meningkatkan wawasan pada anak. (4) meningkatkan kemampuan berpikir pada anak. Kegiatan pengabdian ini bertujuan untuk mengembangkan kemampuan anak-anak selam belajar di masa pandemi agar anak memiliki cara berpikir bahwa belajar itu sepanjang hayat. Inisiatif dari tim pengabdian dalam melaksanakan kegaiatn pengabdaian ini sangat patut diapresiasi dan didukung penuh oleh para pimpinan dan dosen yang telah tergabung dalam tim pengabdian masyarakat dengan melakukan pendampingan dan peningkatan literasi siswa melalui gerekan membaca.

\section{DAFTAR PUSTAKA}

Irdawati; Yunidar; dan Darmawan. "Meningkatkan Kemampuan Membaca Permulaan Dengan Menggunakan Media Gambar Kelas 1 Di Min Buol, ISSN 2354-614X." Jurnal Kreatif Tadulako Online 5, no. 4 (2017): 1-14.

Irna. "Menumbuhkan Minat Baca Anak Usia Dini Melalui Implementasi Literasi Keluarga." Fascho Kajian Pendidikan dan Sosial Kemasyarakatan 1, no. 1 (2019): 15-34.

Kadiwanu, Agriani Stevany. "Gerakan Literasi Nasional, Gerakan Bersama Demi Mencerdaskan Kehidupan Bangsa." BP PAUD DIKMAS NTT.

Nugroho, Iqbal S. "Pembinaan Baca Anak." Merdeka.com 11, no. 2 (2019).

Purnama, Adi Indra, Bazar Efendi, Meilina Setyaningrum, and Susanna Dwi Kartika. "DAMPAK PANDEMI COVID-19 TERHADAP PEMBELAJARAN DARING SEKOLAH DASAR DI DESA CABEAN KECAMATAN DEMAK." Jurnal Online Internasional \& Nasional Vol. 7 No.1, Januari - Juni 2019 Universitas 17 Agustus 1945 Jakarta 53, no. 9 (2019): 1689-1699.

\footnotetext{
${ }^{6}$ Iqbal S Nugroho, "Pembinaan Baca Anak,” Merdeka.com 11, no. 2 (2019).

7 Syaifur Rohman, "Membangun Budaya Membaca Pada Anak Melalui Program Gerakan Literasi Sekolah,” Jurnal Pendidikan dan Pembelajaran Dasar 4, no. 1 (2017): 151-156.
} 
Rohman, Syaifur. "Membangun Budaya Membaca Pada Anak Melalui Program Gerakan Literasi Sekolah." Jurnal Pendidikan dan Pembelajaran Dasar 4, no. 1 (2017): 151-156.

Yuhenita, N N, Y M Majid, and A Murat. "Pendampingan Dalam Menghadapi Pembelajaran Di Masa Pandemi Bagi Warga Dusun Macanan." Selaparang : Jurnal Pengabdian Masyarakat Berkemajuan 4, no. April (2021): 215-219. 